\title{
TRAYECTORIAS DE VIDA ATRAVESADAS POR EL TRABAJO INFANTIL. UN MODO DE HABLAR EL MUNDO CONSTITUIDO COMO DISCURSO MARGINAL
}

\author{
María Luz DAHUL ${ }^{1}$
}

\begin{abstract}
Resumen
En este trabajo recuperamos una entrevista en profundidad realizada a una mujer que se desempeña en el cirujeo y cartoneo $^{2}$ en la ciudad de Mar del Plata. Ella ha sido una niña trabajadora y sus hijos lo son en la actualidad por lo que, el trabajo infantil, atraviesa su trayectoria de vida y la de su familia. El trabajo intenta dar cuenta de su modo de hablar el mundo y de la constitución de un discurso marginal, fuertemente argumentativo, del que se desprende la apelación a prácticas de trabajo infantil como estrategia de vida. El discurso marginal se erige como resistente frente a la existencia de un discurso estándar que tiende a culpabilizar a las familias de los niños y adolescentes trabajadores.
\end{abstract}

Palabras Clave: trabajo infantil - estrategias familiares de vida - discurso marginal discurso estándar

\begin{abstract}
In this paper we recover an in depth interview conducted with a woman who works in the cirujeo and cartoneo in the city of Mar del Plata. She was a working girl and her children are now so, child labor, through their life trajectory and your family. The work tries to account for his speech the world and the establishment of a strongly argumentative marginal speech, the appeal is clear to child labor practices as life strategy. The marginal speech stands as resistant to the existence of a standard speech that tends to blame the families of working children and adolescents.
\end{abstract}

Keywords: child labor - family life strategies - marginal speech - standard speech

\footnotetext{
${ }^{1}$ María Luz Dahul es Licenciada en Servicio Social por la Universidad Nacional de Mar del Plata y maestranda en Trabajo Social por la Universidad Nacional de La Plata. Es becaria de investigación, categoría iniciación, de la UNMDP..lulidahul@hotmail.com

${ }^{2}$ Actividad que implica tanto la recolección de basura de la vía pública o de predios de disposición de residuos, como su posterior clasificación y venta. Dicha actividad es realizada principalmente en carros precarios, impulsados por tracción a sangre, por la propia fuerza de trabajo humana, o por vehículos como bicicletas y motos.
}

Fecha de recepción del artículo: Marzo2016

Fecha de evaluación: Mayo 2016 


\section{Résumé}

Dans cet article, nous récupérons une interview en profondeur menée avec une femme qui travaille dans le cirujeo et cartoneo dans la ville de Mar del Plata. Elle était une fille de travail et ses enfants sont maintenant si, le travail des enfants, par le biais de leur trajectoire de vie et votre famille. Le travail tente de rendre compte de son discours, le monde et la mise en place d'un discours marginal fortement argumentative, l'appel est clair pour les pratiques de travail des enfants comme stratégie de vie. Le discours marginal se présente comme résistant à l'existence d' un discours standard qui a tendance à blâmer les familles des enfants qui travaillent et les adolescents.

Mots clés: le travail des enfants - les stratégies de la vie familiale - discours marginal langue standard

\section{Introducción}

En el presente trabajo ${ }^{3}$ proponemos realizar un análisis semiolingüístico de una entrevista en profundidad realizada a la Sra. C., mujer de 39 años de edad, habitante de la ciudad de Mar del Plata (Partido de General Pueyrredón), madre de 6 hijos, quien se dedica en la actualidad al cirujeo y cartoneo. Para ello como premisa básica es necesario dar cuenta de la concepción de discurso en la que nos basaremos. Tal como afirma Charaudeau, 1988, el discurso es concebido como "el conjunto de actos significativos que hablan el mundo a través de la instancia misma de su transmisión" (Charaudeau, 1988 citado en Fernández y Hachén, 2006: 3). Hablar el mundo implicaría entonces, la posibilidad de construcción del mismo mediante el proceso discursivo. En este sentido, "no hay significados unívocos, sino múltiples significaciones que circulan y se generan a partir del fenómeno de la comunicación” (Fernández y Hachén, 2006: 3).

La entrevista que aquí analizaremos ha sido realizada en el marco del proceso de realización de la Tesis de Grado de la Licenciatura en Servicio Social ${ }^{4}$. La misma tuvo como pretensión aportar a la consideración del trabajo infantil desde una mirada que supere lo legal-normativo y tenga en cuenta el mismo inscripto en el marco de las estrategias familiares de vida adoptadas por sectores pobres urbanos de la zona puertosur de la ciudad de Mar del Plata para el período abarcado entre 2011 y 2013.

El acercamiento a la problemática y la construcción del problema de conocimiento estuvo precedido por la realización de práctica organizacional supervisada ${ }^{5}$ de la autora en un programa de prevención de trabajo infantil ${ }^{6}$ del que la entrevistada y su familia, específicamente sus hijos e hijas, participan. Se enfatiza en ello en tanto es importante destacar que existe entre la entrevistadora y la entrevistada un vínculo de confianza y

\footnotetext{
${ }^{3}$ Una versión preliminar de este trabajo ha sido presentada en función de la aprobación del Seminario “Aportes de la Semiótica y la Lingüística a la Investigación Social”, a cargo de la Dra. María del Rosario Fernández, en el acuerdo UNMDP-ADUM.

${ }^{4}$ La Licenciatura en Servicio Social a la que nos referimos pertenece a la órbita de la Universidad Nacional de Mar del Plata. La misma fue realizada con la dirección de la Lic. Paula Meschini y la codirección de la Mg. María Eugenia Labrunée, ambas docentes investigadoras de la UNMDP. Puede ser visitada en http://nulan.mdp.edu.ar/1841/1/dahul_ml_2013.pdf

${ }^{5}$ La práctica organizacional supervisada se realizó en el marco de la cátedra Supervisión ubicada en el último año del Plan de Estudios de la Lic. en Servicio Social de la UNMDP.

${ }^{6}$ Programa de prevención de Trabajo Infantil inscripto en la lógica de la cuestionable responsabilidad social empresaria, financiado por Fundación Telefónica y ejecutado por la OSC Conciencia en el que se permaneció trabajando hasta diciembre de 2014. Su denominación formal hasta 2012 fue Programa Proniño, para luego pasar a denominarse TaTeTi.
} 
conocimiento mutuo, construido en el pasado, que podría posibilitar el arribo conjunto a determinadas conclusiones que sin la constitución del mismo tal vez no habrían sido posibles. Consideramos necesario aclararlo, en tanto "el analista tiene la obligación de revisar y exponer su propio proceso analítico y sus procedimientos tan completa y verazmente como le sea posible" (Vasilachis de Gialdino, 2006: 5). No obstante ello, somos conscientes de que la construcción de tal vínculo ha estado mediada por las representaciones que en el imaginario social se tengan de las prácticas preprofesionales de Trabajo Social y/o del programa en que dicha práctica fue realizada.

El análisis que proponemos es realizado desde un enfoque semiolingüístico entendiendo que el mismo posibilita dar cuenta del proceso discursivo. Tal como afirman Fernández \& Hachén (2006) la semiolingüística utiliza la lingüística como ciencia instrumental y la semiótica como ciencia explicativa. Por último, recordando "la función explicativa de la semiótica puesto que ella nos remite a la noción de no trasparencia del texto" (Fernández \& Hachén, 2006: 29) es necesario afirmar que el análisis realizado no es el único posible sino el que como sujetos intérpretes proponemos.

Por ello, a modo de supuesto de lectura e interpretativo sostendremos que el discurso de la entrevistada se erige como discurso marginal, al que se impone la standarización de ese 'otro' discurso, el que señala la "normalidad", el "deber ser" y la "normativa" en este caso en relación a las prácticas del trabajo infantil. Con base en este discurso estandarizado, con frecuencia se suele culpabilizar a los adultos que incluyen a niños, niñas y adolescentes en actividades laborales sin reparar en los análisis que permitan desentramar cuáles son las condiciones de posibilidad para la existencia de prácticas de trabajo infantil. Como afirma Pedraza Gómez (2007) a menudo, se "desvía la atención de las verdaderas causas y del origen de la vergüenza que no le corresponde sentirla a las familias de los niños trabajadores" (Pedraza Gómez, 2007: 89). La recurrencia a estos modos de hablar respecto a la problemática, no sólo se encuentran presentes en comentarios callejeros o de Doña Rosa sino también, en ocasiones, en argumentos de profesionales intervinientes.

Tal como sostienen Fernández y Hachén (1991) la relación entre discurso standard y discurso marginal debe ser pensada como una relación entre elementos constantes.

[...] que en la trama significativa de la cultura, en un preciso momento se perciba un discurso como marginal o como standard no es más que un fenómeno de interpretación colectiva que responde al predomino de cierta voz (lo cual no implica que esa sea la única voz, ni la mejor, ni la verdadera) sino simplemente que es la que a un cierto grupo se le impone (Fernández y Hachén, 1991: 4).

En tanto los discursos hablan el mundo y construyen significaciones, a través del análisis presentado intentaremos dar cuenta de cómo es concebido el trabajo infantil desde el modo de hablar el mundo de la entrevistada y cómo su discurso es construido desde la argumentación, buscando no salirse de los límites impuestos desde la mirada de aquel destinador justiciero (Costa \& Mozejko, 2001) que se constituye como fuente de legitimación de lo narrable.

¿A qué nos referimos con trabajo infantil? Breves notas sobre su concepción y sobre la normativa vigente en Argentina 
Por trabajo infantil -en consonancia con los plexos normativos existentes en Argentinase entiende, en principio, a aquella actividad económica remunerada o no, realizada por menores de 16 años bajo el supuesto de que la misma constituye un obstáculo para la concreción de sus derechos universalmente declarados, interviniendo en el desarrollo integral del niño o joven (Macri et al 2005, Macri 2011, Ministerio de Trabajo, Empleo y Seguridad Social de la Nación, Ley Nacional 26.390).

La Ley Nacional 26.390, sancionada en 2008, eleva la edad mínima de admisión al empleo a 16 años -anteriormente era de 14 años- y crea la figura de trabajo adolescente protegido para adolescentes de 16 y 17 años. Asimismo, en 2013, se incorpora al Código Penal el artículo 148 bis que prevé la sanción privativa de la libertad de uno a cuatro años de prisión para aquellos que se aprovechen del trabajo de niños y niñas sanción de la que se hayan exentos los padres de los niños, niñas y adolescentes.

\section{$\underline{\text { La entrevista }^{7}}$}

A continuación se transcribe textualmente la entrevista realizada con C. Posteriormente, se realiza el análisis correspondiente.

[...] A trabajar empecé a los 9 años en el saladero, en el descabezado de anchoítas. Este... después bueno fue en el tiempo así, trabajé hasta los 15 años más o menos. A la escuela me mandaron hasta 2 do grado y después mamá y papá me mandaron a trabajar al saladero y dejé de trabajar [confusión] de... ir al colegio. Y bueno después me hice grande [risas], ya después dejé el colegio definitivamente y bueno así empezaron a venir... Ma. [hija mayor], ya estaba grande y empezaron a venir casi a los 20 años mi hija, la mayor, de 18 años. Pero no, bueno...trabajando, en la lucha.

Edora. ${ }^{8}: ¿$ de quién fue la decisión de que empieces a trabajar?

$\mathrm{Ea}^{9}$ : De mi papá y de mi mamá, ellos me mandaban.

Edora.: ¿Ibas junto con ellos a trabajar? [Interrupción de la entrevistadora]

Ea: Con mi mamá y así...

Edora.: Tus hermanos o alguien más iba?

\footnotetext{
${ }^{7}$ La entrevista fue realizada en febrero de 2013. La entrevistada, conociendo el objetivo de la misma, brindó su consentimiento para ello. Transcripción textual de la grabación. En ocasiones, se omitieron partes de la misma debido a comentarios que corresponden a la intimidad de la familia y no tienen consecuencias en el análisis. En esos casos se representa en el texto con el símbolo [...]. Los nombres de las personas involucradas has sido sustituidos por iniciales para el resguardo de su identidad.

${ }^{8}$ Abreviatura de entrevistadora.

${ }^{9}$ Abreviatura de entrevistada.
} 
Ea: Nonono, después mis hermanas después también fueron grandes y también [aseveración de ese también] las mandó a trabajar. A todos los empezó a mandar a trabajar. Y bueno... a trabajar, a trabajar y a trabajar para ellos no más.

Edora.: ¿Te pagaban ahí? y esa plata ¿la tenías para vos?

Ea: Nono, la daba a mi mamá, se la dábamos para ella. Trabajábamos para ella. Trabajábamos para la casa.

Edora.: y de la escuela ¿te acordas algo? ¿A qué escuela ibas? ¿Te gustaba?

Ea: Si, estaba bueno. Primero fui a la 44 a la que está ahí... [confusión] No, a la 42 fui. Después, bueno, después me mandaron a la 506, porque ya estaba grande, a los 15 años y yo ya no sabía leer ni nada y me mandaron ahí. Y bueno ya después a los 17, 18 dejé el colegio no? tenía 16, 17, 18 años y ya iba a ler grado entonces no... Como nunca me mandaron al colegio, me mandaban a la vista perdida y bueno...

Edora.: ¿Y en ese momento vos que hacías? trabajabas e ibas a la escuela también?

Ea: Si, iba a la escuela y trabajaba. Después bueno... dejé la escuela definitivamente, de grande. Y después me anoté de noche acá en la 64, que vivía con mi hermana ya ahí yo, y mi finado cuñado. Ellos me mandaban a la escuela y me compraban la ropa porque yo era niñera de ellos. Y les cuidé a ellos un montón de años, la casa y los nenes, si... y ellos me mandaban a la 64 de noche. Y bueno después bueno, ya me fui haciendo grande, este me fui haciendo grande y bueno... a los 20 años, 21 ya tuve a Ma., me faltaban 10 días [para cumplir los 21 años], la mayor.

Edora.: ¿en qué otras cosas has trabajado?

Ea: En la fábrica, en Muimesi, estuve 14 años efectiva.... [Interrupción, charla con una de sus hijas], Este como es, estuve 14 años en Muimesi, tuve a Ma.

Edora.: ¿Eso fue cuando estabas embarazada de Ma.?

Ea: No, ya estaba nacida mi hija, tenía 10 días mi hija cuando yo empecé a trabajar. Si... y después más o menos a los 12, 13 años yo ya dejé de trabajar en la fábrica...

Edora.: ¿Y ahí te fuiste porque vos quisiste, cómo fue?

Ea: Nonono, porque me llevaba mal con mi mamá. Porque como yo estaba sola viste y con los chicos...que ella quería la plata, la plata, la plata, la plata y yo no se la podía dar porque yo ya era mayor y tenía la nena. Y bueno después vino Al. [hijo], y bueno y así vinieron todos los chicos. Para ver si podía [aseveración en el podía] tener una familia, pero bueno...no tuve la suerte con los papás de los chicos... Ahora con el papá de T. [hijo menor] gracias a dios... buenísimo hace 8 años que está conmigo pero bueno, no nos hace falta la comida y...

Edora.: ¿Y M. C [pareja de la entrevistada] está trabajando?

Ea: Él estaba trabajando en el puerto, ellos eran del lavadero de cajón, estaba trabajando bien... 
Edora.: ¿Y ahí estaba en efectivo o algo?

Ea: Nono, estaba por mes, trabajaba por mes. Bueno después con una decisión mía, que no se qué pasó...tuvo que dejar de trabajar él para cuidar los nenes y yo irme a un trabajo, que era de cuidar niños, que trabajé de cuidar chicos. Bueno trabajé de cuidar chicos, T. se me enfermó, quedó 15 días T. internado...

Edora.: ¿Eso cuándo fue?

Ea: Era chiquito. Tenía infección urinaria y bueno... perdí el trabajo. Porque uno de los dos teníamos que trabajar y cuidar al nene y ahi fue que dejé el trabajo.

Edora.: ¿Y ahí por ejemplo siempre ellos [sus hijos] te ayudaban a cuidar a los chicos y eso?

Ea: Si si, los hermanos me ayudaban un montón a cuidar a los chicos. La mayor y A. y ahora M., [hijas mujeres] todo. Y bueno, y ahora salimos con el carrito a cirujear.

Edora.: ¿Y ahora como esta eso? ¿Pueden salir tranquilos? [anteriores problemas con el municipio]

Ea: Nonono, como salimos con el carrito a mano... no pasa nada, ya no nos molestan, no pasa nada.

[Interrupción. Llega M. C. pareja de la entrevistada.]

Ea: Este como es... salimos con el carrito a mano y bueno... y no hay problema.

Edora.: ¿Y los chicos van con ustedes?

Ea: Si, nono yo me los llevo. Si me los llevo acá solos no los dejo.

Edora.: ¿Preferís que vayan con ustedes?

Ea: Nonono, sisisi. Si los más chiquitos van todos con nosotros, no no los dejo acá por el tema del fuego... o de la luz o siempre algo hacen, viste... entonces me los llevo conmigo a los tres más chiquitos.

Edora.: ¿Y A., M. y Al. se quedan? [hijos]

Ea: No, A. [confusión, se refiere a M.] va con nosotros, no ella va con nosotros, yo no la dejo a ella. Porque dos por tres viste se pelean con las nenas viste que M. veni a barrer, que yo lavo los platos y vos barres. Entonces viste... para hacerla descansar la flaca va conmigo, se va conmigo la flaqui y el papá.

Edora.: ¿Y a los chicos en la escuela como les ha ido?

Ea: Todo bien, gracias a dios me pasaron todos de grado. Todo bien gracias a dios todos van a la escuela [aseveración en el todos]. Hasta el muchachito al jardín [refiriéndose a su hijo más chico], T. va al jardín.

[Interrupción conversación con los niños.] 
Edora.: ¿Y a ellos les gusta la escuela, qué dicen?

Ea: $S i \ldots$

Pareja de la Ea: Bueno los chicos más chicos sí, vos notas que les gusta. Cuando empiezan a crecer, viste que empiezan la adolescencia tenes que estar atrás de ellos para que sigan viste...

Edora.: ¿Y Al. sigue la escuela? [hijo de 16 años]

Ea: No. Al. ahora va a seguir pero me dejó, a la mitad de año me dejó. Y ahora sigue, ahora el 20, el 21 cuando vaya A. se va a ir a anotar... de vuelta.

Pareja de la Ea: Si, un curso, algo, que salga de la casa. Aunque sea un curso donde vos puedas aprender y hacer algo que a vos te guste.

Edora.: ¿M. C. vos sos de Buenos Aires no?

Pareja de la Ea.: $S i$.

Edora.: ¿Y allá hiciste la escuela?

Pareja de la Ea.: Yo termine todo, termine acá en Mar del Plata.

Edora.: ¿Qué terminaste, el secundario?

Pareja de la Ea.: No, primer año de bachiller.

Edora.: Si, si C. siempre me contaba...

Ea: Tiene la esposa burra y el marido inteligente...

Edora.: No... ¿por qué? cada uno sabe cosas diferentes

[Risas]

Edora.: Cuando ustedes se tienen que ir o algo y los chicos se quedan acá, como recién me decían que A. y Al. se quedan, [y Ma. la mayor agrega la entrevistada] ¿hacen algo?

Ea.: Hace dos semanas que vive conmigo mi hija gracias a dios.

Edora.: ¿Y le salió algún trabajo de peluquería?

Ea.: No, no. Porque las herramientas que necesita ella, las tijeras todo eso son muy caras, y yo no se lo puedo comprar L. [refiriéndose a la Edora.], con la situación que estamos pasando nosotros no se la podemos comprar... Y bueno, ahora ayer agarró un trabajito de cuidar nenas, $\$ 40$ la hora, es un rato no más, de las 12 a las 4 de la tarde, $\$ 40$ por día. Bueno asique, ahora hace un ratito fue a llevar las nenas. Mamá a las 4 y media estoy acá, bueno le digo. Asique vamos a ver.

Pareja de la Ea.: El tema es que a veces le digo que ella no es tanto, porque ella quiere empezar a cortar el pelo pero pasa que como le falta práctica ella no quiere quedar con nadie mal entonces ella quiere seguir pero que le den más enseñanza, más práctica que lo que ya tuvo. Asique le dije que más o menos para el año que viene, ahí en Luro hay 
una que es todo práctica, está al frente de la terminal, es todo práctica, es una escuela que todos los chicos van aprendiendo y los mayores, los que saben van diciéndoles que tienen que hacer.

Ea.: Claro...

Edora.: Esta bueno eso, o por ahí de ayudante en alguna peluquería

Ea.: Si... hoy llamaron a la radio también que querían para limpieza, para cuidar chicos, para cuidar abuelas... Te encargo vos L., para cuidar algún abuelito, abuelita...yo que se para limpiar una casa, cualquier cosa, ahora que vamos a estar allá arriba [refiriéndose a posibilidad de mudanza]

Edora.: Si más vale

Ea: Uno necesita trabajar a full, a terminar de pagar el terrenito y bueno, a empezar con la casita, si dios quiere.

Edora.: ¿La plata de la Asignación ${ }^{10}$ les ayuda para eso también?

Ea.: y... ahora la voy a usar este mes porque los voy a mandar en marzo yo recién a los nenes ... a la escuela. Porque este mes voy a pagar el terreno para que poder entrar yo al terreno [aseveración en el poder]. Para que ellos, el día de mañana, que sea de ellos L. Que no tengan que andar aguantando lo que yo aguanto con mi mamá y mi papá me entendés. Entonces para decir...yo no voy a decir: "Hija, andate porque te tenés que ir". Yo no le voy a decir, porque yo cuando ellos crezcan anda a saber si yo estoy viva todavía...me entendés... entonces yo quiero para ellos. Ya está basta, yo, demasiado viví acá bueno. Y esto es mío L. eh!!! [Énfasis en la frase] esto es mío!!! Sabes lo que yo anduve cuando vinimos debajo de esa planta? vinimos mi papá, mi hermano J., yo y mi hermana $V$., mi mamá estaba juntada acá abajo en la diagonal con otro hombre, esto es de nosotros esto es mio! de J., mi hermano y la $V$., y mi viejo porque nos vinimos los 4 a vivir acá, con un camión, de Maipú veníamos.

Edora.: ¿Vos naciste en Maipú?

Ea.: Nono no yo nací acá, yo soy criada y nacida acá pero cuando nosotros estábamos viviendo en Maipú, mi mamá bueno... se vino, se fue, se vino a vivir sola para acá con este hombre y mi papá estaba enfermo allá y bueno...empezó a sufrir del asma porque chupaba mucho, viste... el asma, el corazón, todo eso y bueno nosotros nos vinimos a vivir para acá... y encontramos este terreno, si acá no era calle...no era calle, estaba todo cerrado de mugre, parecía un basural...y el pasto era pasando el techo cuando nosotros vinimos a vivir acá...

$[\ldots]$

Pareja de la Ea.: [en relación a pago de terreno] Venía hablando y hablando hasta que bueno, lo que pasa que no me daba el cuero para darle la plata que él nos pedía. Porque nos pide $\$ 5000$ [aclara la Ea.] [vuelve a hablar pareja] Asique le fui hablando y le dije, mira... yo estoy con un carrito a mano, yo me subo la loma, bajo la loma, no

${ }^{10}$ En referencia a Asignación Universal por Hijo para la protección social. 
tengo problema en pagártelo pero necesito arrancar.... "y si pero yo tampoco te lo puedo dar sin plata" me dice.

Ea.: Asique yo la asignación que cobro mañana....

Pareja de a Ea.: y conocía a un primo de nosotros asique estuvimos hablando ahí un rato los tres...para llegar a un acuerdo.

Ea.: Son $\$ 200$ pesos por semana que nose... algo vamos a hacer... Lo que pasa que yo le digo "M. C, es muy alto para vos que vayas en el carro y vuelvas en el carro" se me va a enfermar... es muy alta la lomada negra... muy muy es mucho para subir y tenes que hacer los $\$ 200$ en el carro eh!!!porque no vale nada la chatarra gorda...no vale nada...

Edora.: ¿Más o menos ustedes cuánto sacan?

Ea.: por semana... \$250, \$300... Se hace dificil, que va a ser ...pero bueno hay que vivir con la ayuda...

Pareja de la Ea.: Lo bueno viste que el tema comida, viste mangueamos, que se yo...yo tengo de la pollería, rescato un poco de la calle...o carnicerías y así... y bueno eso ayuda bastante... más lo que uno se manguea...

Ea.: Y ahora la escuela a los chicos no los voy a poder mandar bueno, por el tema este, yo quiero irme de acá... aparte Al. también me pide, ellos también me piden que ellos no quieren que estean más acá... Ya en marzo ya los mando en marzo... a mí lo que me cuesta más son las cosas de la escuela de ellos...

Edora.: ¿Y eso como lo consiguen?

Ea.: Claro, porque los chicos empiezan ahora el 25, ahora este mes, pero si yo les compro las cosas no puedo pagar, yo no soy, L. Para el jardín de T. tengo que darle $\$ 100$ porque los útiles de todo el año...que si no tengo que comprar, cuánto me sale a mi todos los útiles de T. para el jardín?... [énfasis en el cuánto]

Pareja de la Ea.: Igual yo les voy juntando, siempre me dan lápices...

Ea.: y así que va ser... Lo que sea ...yo salgo en el carrito eh!! ojo que yo también salgo [alarga el salgo], si, yo también salgo... Él sale con los nenes, y sino salimos todos juntos... yo y él y los nenes... o sino salgo yo y M., y A., salimos todos juntos y los llevamos a las 4 manzanas a las plazas allá... y ahí les compramos una gaseosa, les hacemos jugar un rato viste para que no se maten ellos tampoco viste pobrecitos... hacemos pic nic nosotros vamos cirujeando, juntando cartón y eso y de paso ellos pasean también un rato... y si porque si acá ya no se puede andar ya por esa calle...es terrible lo que afaltaron $L$. ., desastre es esto de noche...de noche y de día... los pendejos en las motos es un desastre... no podes estar con los muchachitos en la calle.

Pareja de la Ea.: Encima vino el tranza ese de vuelta a este barrio.

$[\ldots]$

Pareja de la Ea.: Pero bueno viste siempre caes en la volteada... 
Ea.: Entonces no... nos vamos a la mierda... a mi viene entra en chabón me pega una patada, si mirá lo que es esa puerta... viene me mata todos los chicos acá adentro...todos los chicos durmiendo...y a nosotros también durmiendo... no puedo vivir asi L. yo. No, no, no, por lo nenes, no. Ya una vuelta por defender a mi hermano casi más nos matan a los dos, no, no sabes la que pasamos nosotros allá arriba culpa de mi hermano!! [Cuenta la historia en pasado] no quiero volver a pasarlo, yo no voy a subir en el bondi de los demás, se terminó L.... cuando yo volví a vivir acá a mí el chabón no me abrió la puerta, mi hermano Li. [por quien tuvieron los problemas contados] me dejó bien re tirada [énfasis en el bien], porque me dejó bien tirada...[nuevamente énfasis en el bien] El sábado cuando pasó este quilombo que pun y que pan le digo Li. le digo, no me haces la gauchada te llevas los nenes para allá? yo me quedo con M.C. acá a hacer tiempo porque me van a matar, me van a matar a mí, está todo bien, van a sufrir mis hijos, les van a matar los papás, está todo bien... pero mis hijos? "no no dice porque quedate porque nose que..." se lavó las manos el chabón... le digo a M.C. si tenían que venir a hacernos algo... no hicimos nada L. nosotros eh, te lo juro que no hicimos nada...este bardió y nos echó las culpas a nosotros, nada que ver si nosotros andamos todo el día en el carrito...y bueno... es lo mismo que yo me mande una cagada y te eche las culpas a vos, el chabón a quien va a agarrar? a vos ... y vos no hiciste nada!!! Entonces vos que tenés que hacer? defender a tus hijitos si vos no hiciste nada!!!porque sabes que ese chabón va a venir...nosotros no molestamos a nadie

Edora.: ¿y en casos así cuentan con alguien, algún vecino, amigos?

Ea.: Yo estaba segura de contar con mi vecino, pero ahora le prometió el tiro a mi marido que prendió fuego viste...y y fue se terminó. Después que le ayudé, fui al velorio, fui al entierro de la tía, la madre, el padre no sé quién mierda era...le limpié toda la casa cuando ella estaba embarazada viste...si después te pagan así...no ya fue, cada uno para su rancho... yo acá y vos allá, nos vemos.

Edora.: ¿Los chicos que hacen? bueno van a la escuela y cuando no van a la escuela que hacen, salen a veces con ustedes en el carrito....

Ea.: Y después no, todo el día acá adentro están, juegan acá todo, no no, no salen a ningún lado, salen conmigo ellos o no salen. Los tres más chiquitos salen conmigo...

Edora.: ¿Y ellos te ayudan, los nenes y las nenas, en las mismas cosas o...?

Ea.: No no no, las chicas cuando yo salgo así con el papá ellas limpian la cocina, o una hace las piezas, o la otra, yo que sé, barre el patio o la otra limpia el baño... el otro más grande que es Al. se limpia, se lava su pieza, hace su pieza y como es... lava su ropa, yo no le lavo la ropa de él...no no se lava sólo, medio mariqui...no, se lava la ropa solito él...

Un análisis semiolingüístico posible de la entrevista. Cuando el modo de hablar el mundo es constituido como discurso marginal

Tal como mencionamos más arriba, podemos visualizar en el desarrollo de la entrevista la construcción de un discurso marginal, no porque haya discursos que en sí mismo lo 
sean sino entendido éste en términos relacionales con ese 'otro' discurso -el standarizado-.

De acuerdo a las afirmaciones de Hachén (1999) hay determinados discursos que se han convertido, o han querido convertirse, en las únicas caras de la verdad. Así, "si existe un "deber", es porque hay un "poder" que lo instaura y lo determina, asociado al "saber"," (Hachén, 1999: 5).

En este sentido, a partir del supuesto de lectura planteado podemos visualizar cómo la entrevistada relata prácticas cotidianas suyas y de su grupo familiar que interpelan desde la realidad que se les impone, a las necesarias pero insuficientes normativas creadas en torno al trabajo infantil. Así, las prácticas de trabajo infantil se encuentran enmarcadas en estrategias de cuidado que las familias recrean antes las situaciones presentadas. Resulta significativo evidenciar cómo la inclusión en actividades laborales se vinculan y son vivenciadas como prácticas lúdicas y de descanso. Si desde un discurso standarizado el ir a cirujear se constituye como práctica de trabajo infantil y des-cuidado por parte de los adultos, desde el modo de hablar el mundo de la entrevistada vemos como en esa incorporación al trabajo recrean prácticas lúdicas y de cuidado. Al respecto menciona "Entonces viste... para hacerla descansar la flaca va conmigo, se va conmigo la flaqui y el papá" [en relación a trabajar en el carro] o "salimos todos juntos y los llevamos a las 4 manzanas a las plazas allá... y ahi les compramos una gaseosa, les hacemos jugar un rato viste para que no se maten ellos tampoco viste pobrecitos... hacemos pic nic nosotros vamos cirujeando, juntando cartón y eso y de paso ellos pasean también un rato... y si porque si acá ya no se puede andar ya por esa calle...es terrible lo que afaltaron $L$. ., desastre es esto de noche...de noche y de dia...".

En términos de Maingueneau (2004) es interesante introducirnos en la noción de escena de enunciación. Tal como afirma el autor, para comprender la misma es importante distinguir tres escenas que se vinculan complementariamente, estas son: la escena englobadora, la escena genérica y la escenografía. Podríamos decir que la constitución de escenas enunciadoras en el texto que aquí nos compete tiene que ver con la construcción de un discurso antropológico como escena englobadora, el desarrollo de la entrevista en profundidad como escena genérica y la construcción del discurso marginal como escenografía. Tal como afirma Maingueneau

[...]La escenografía no es un simple marco o decorado. No se trata de que el discurso surja en el interior de un espacio ya construido -e independiente de ese mismo discurso- sino de que la enunciación, en su devenir, se esfuerza por poner progresivamente en funcionamiento su propio dispositivo de habla [...] La escenografía resulta así, simultáneamente, aquello de donde el discurso proviene y aquello que el mismo discurso genera (Maingueneau, 2004: 5)

En este sentido, como marcas constitutivas de la escenografía en el discurso que nos han servido para el análisis de la presente entrevista en profundidad dentro de la construcción de un discurso marginal, encontramos una fuerte modalidad argumentativa del discurso, la utilización de conectores que dan cuenta de una focalización causal, presencia de respuestas en vinculación a una modalidad deóntica, cita de voces de autoridad e inclusión de testigos que sirven de justificación a lo planteado por la entrevistada, búsqueda la constante aceptación por parte de la entrevistadora -no por lo que la entrevistadora en sí misma represente sino tal vez por asociarla con cierto 
discurso standarizado o que representa el deber ser-, la utilización de tiempos comentativos que permitan adentrarnos en el discurso desde una posición de mayor alerta, el pasaje de un narrador autodiegético en primera persona al heterodiegético en determinados momentos significativos en los que la entrevistada se distancia e intenta mantenerse por fuera de la diégesis.

A continuación desarrollaremos lo aquí planteado vinculándolo con ejemplos que hemos considerado ilustrativos y nos han permitido construir el supuesto interpretativo. Recordemos una vez más, que el análisis realizado, lejos de constituirse como verdad única, es parte del supuesto interpretativo que presentamos.

Evidenciamos la frecuencia a lo largo del cuerpo del discurso de la modalidad argumentativa. Tanto la entrevistada como su pareja -quien interviene en ocasiones en la entrevista- construyen un tipo de discurso basado en la argumentación y su función justificativa (Lo Cascio, 1991). De acuerdo con Lo Cascio se entiende a la argumentación como

[...] Un acto de habla formado por una constelación de afirmaciones destinadas a justificar o rechazar una opinión, y concretadas en una discusión organizada, para convencer a un juez racional sobre un punto de vista particular con relación con la aceptabilidad o falta de ésta en una opinión expresada (Lo Cascio, 1991: 90 en Fernandez y Hachén, 2002: 1341).

En este sentido, es interesante distinguir cómo en el discurso de ambos hay constantes interacciones con la entrevistadora, mediante palabras y frases que buscan, aunque de modo pre-reflexivo, su aceptación y consenso. En este sentido es frecuente el uso de frases como "viste..." "me entendés?" o la puesta de ejemplos que involucran a ambas dentro de la escena relatada. Entendemos que la necesidad de argumentar las prácticas, tiene que ver con la necesidad de justificación y búsqueda de aceptación de aquel destinador justiciero al que, en el plano de lo simbólico, se lo representaría como conocedor y representando por el discurso estándar.

Asimismo, podemos evidenciar cómo ante preguntas que en el imaginario social se vinculan al campo del 'deber ser' -nos referimos a aquellas preguntas que involucran a los niños, niñas y adolescentes en actividades laborales, ya sea que acompañen a los adultos en sus actividades o que se encarguen del trabajo doméstico- las respuestas de la entrevistada van acompañadas de la negación en primera instancia, argumentando y justificando el porqué de aquel aparente incumplimiento de lo que la normativa exige, vinculando entonces sus respuestas con una modalidad deóntica. A modo de ejemplo seleccionamos el siguiente fragmento

[...] Edora.: ¿Y los chicos van con ustedes? Ea: Si, nono yo me los llevo. Si me los llevo acá solos no los dejo. Edora.: ¿Preferís que vayan con ustedes? Ea: Nonono, sisisi. Si los más chiquitos van todos con nosotros, no no los dejo aca por el tema del fuego... o de la luz o siempre algo hacen, viste... entonces me los llevo conmigo a los tres más chiquitos. Edora.: ¿Y A., M. y Al. se quedan? [hijos] Ea: No, A. [confusión, se refiere a M.] va con nosotros, no ella va con nosotros, yo no la dejo a ella. [...] Edora.: ¿Los chicos que hacen? bueno van a la escuela y cuando no van a la escuela que hacen, salen a veces con ustedes en el carrito.... Ea.: Y después no, todo el día acá adentro están, juegan acá todo, 
no no, no salen a ningún lado, salen conmigo ellos o no salen. Los tres más chiquitos salen conmigo... Edora.: ¿Y ellos te ayudan, los nenes y las nenas, en las mismas cosas o...? Ea.: No no no, las chicas cuando yo salgo así con el papá ellas limpian la cocina, o una hace las piezas, o la otra, yo que sé, barre el patio o la otra limpia el baño... el otro más grande que es Al. se limpia, se lava su pieza, hace su pieza y como es... lava su ropa, yo no le lavo la ropa de él...no no se lava sólo, medio mariqui...no, se lava la ropa solito él...

Asimismo, en el siguiente ejemplo podemos ver cómo la entrevistada a modo de cita de voces de autoridad o como parte de una estrategia de verosimilitud realista, vincula el texto con el entretexto e incluye testigos que justifican y refuerzan la decisión que en esta oportunidad ha tomado, decisión nuevamente que desde el discurso standarizado no sería legitimada. Así, da cuenta del pedido de sus hijos de mudarse, relacionándolo con la justificación que siente que debe brindar al porqué de no mandar a sus hijos a la escuela e invertir el dinero de la Asignación Universal por Hijo para la protección social para de pago de la cuota del terreno.

[...]Ea.: Y ahora la escuela a los chicos no los voy a poder mandar bueno, por el tema este, yo quiero irme de acá... aparte Al. también me pide, ellos también me piden que ellos no quieren que estean más acá... Ya en marzo ya los mando en marzo... a mi lo que me cuesta más son las cosas de la escuela de ellos...

En vinculación con lo anterior, hay un énfasis en relaciones causales explícitas, evidenciándose la utilización frecuente de conectores que permiten entrever un tipo de focalización basada en la causa, tal como afirma Portolés (1998).

Edora.: ¿La plata de la Asignación les ayuda para eso también? Ea.: y... ahora la voy a usar este mes porque los voy a mandar en marzo yo recién a los nenes... a la escuela. Porque este mes voy a pagar el terreno para que poder entrar yo al terreno [aseveración en el poder]. Para que ellos, el día de mañana, que sea de ellos L. Que no tengan que andar aguantando lo que yo aguanto con mi mamá y mi papá me entendés. Entonces para decir...yo no voy a decir: "Hija, andate porque te tenés que ir". Yo no le voy a decir, porque yo cuando ellos crezcan anda a saber si yo estoy viva todavía...me entendés... entonces yo quiero para ellos. Ya esta basta, yo, demasiado viví acá bueno. Y esto es mío L. eh!!! [Énfasis en la frase] esto es mío!!! sabes lo que yo anduve cuando vinimos debajo de esa planta? vinimos mi papá, mi hermano J., yo y mi hermana $V$., mi mamá estaba juntada aca abajo en la diagonal con otro hombre, esto es de nosotros esto es mio! de J., mi hermano y la $V$., y mi viejo porque nos vinimos los 4 a vivir acá, con un camión, de Maipú veníamos.

Asimismo y en relación con la constitución de un discurso marginal, basado en lo argumentativo, en el que la cuestión evaluadora del narrador se presenta constantemente buscando la aprobación de aquel destinador justiciero, es interesante dar cuenta de la utilización de tiempos comentativos (Weinrich, 1979) en ciertos momentos de la entrevista, en los que la entrevistada y su pareja se van más movilizados, relatan cuestiones vinculadas a relaciones conflictivas de su vida privada, en las que se puede evidenciar la presencia de situaciones que suscitan incertidumbre $\mathrm{y}$, en ocasiones, peligro, que requieren un grado de alerta máximo por parte de quien escucha. En este sentido, tal como afirma Marafioti (1997) mediante la utilización de tiempos 
comentativos se hace saber al interlocutor que el texto merece de su parte una atención vigilante (grado de alerta II) otorgando vivacidad y actualidad al relato.

Además en el siguiente ejemplo, podemos visualizar la utilización de la gradualidad por parte de la entrevistada quien al realizarlo da cuenta desde lo discursivo tanto del abandono de su hermano, como luego el sacrificio de su pareja.

[...]Pareja de la Ea.: Hay que empezar de nuevo Ea.: [...] asique no podemos tener visita no podemos tener nada. Asique vamos a tener que irnos le digo a M.C., vamos a tener que irnos, vamos a tener que irnos... Pareja de la Ea.: Venía hablando y hablando hasta que bueno, lo que pasa que no me daba el cuero para darle la plata que él nos pedía. Porque nos pide \$5000 [aclara la Ea.] [vuelve a hablar pareja] Asique le fui hablando y le dije, mira... yo estoy con un carrito a mano, yo me subo la loma, bajo la loma, no tengo problema en pagártelo pero necesito arrancar.... "y si pero yo tampoco te lo puedo dar sin plata" me dice. [...]Ea.: Entonces no... nos vamos a la mierda.... a mi viene entra en chabón me pega una patada, si mirá lo que es esa puerta... viene me mata todos los chicos acá adentro...todos los chicos durmiendo...y a nosotros también durmiendo... no puedo vivir asi L. yo. No, no, no, por lo nenes, no. Ya una vuelta por defender a mi hermano casi más nos matan a los dos, no, no sabes la que pasamos nosotros allá arriba culpa de mi hermano!! [Cuenta la historia en pasado] no quiero volver a pasarlo, yo no voy a subir en el bondi de los demás, se terminó L.... cuando yo volví a vivir acá a mi el chabón no me abrió la puerta, mi hermano Li. [por quien tuvieron los problemas contados] me dejó bien re tirada [énfasis en el bien], porque me dejó bien tirada...[nuevamente énfasis en el bien] El sábado cuando pasó este quilombo que pun y que pan le digo Li. le digo, no me haces la gauchada te llevas los nenes para allá? yo me quedo con M.C. acá a hacer tiempo porque me van a matar, me van a matar a mí, está todo bien, van a sufrir mis hijos, les van a matar los papás, esta todo bien... pero mis hijos? "no no dice porque quedate porque nose que..." se lavó las manos el chabón... le digo a M.C. si tenían que venir a hacernos algo... no hicimos nada L. nosotros eh, te lo juro que no hicimos nada...este bardió y nos echo las culpas a nosotros, nada que ver si nosotros andamos todo el día en el carrito...y bueno... es lo mismo que yo me mande una cagada y te eche las culpas a vos, el chabón a quien va a agarrar? a vos... y vos no hiciste nada!!! entonces vos que tenés que hacer? defender a tus hijitos si vos no hiciste nada!!!porque sabes que ese chabón va a venir...nosotros no molestamos nadie

\section{$[\ldots]$}

Ea.: Son $\$ 200$ pesos por semana que nose... algo vamos a hacer... Lo que pasa que yo le digo "M.C, es muy alto para vos que vayas en el carro y vuelvas en el carro" se me va a enfermar ... es muy alta la lomada negra... muy muy es mucho para subir y tenes que hacer los $\$ 200$ en el carro eh!!!porque no vale nada la chatarra gorda...no vale nada...

Continuando, a partir del análisis discursivo de la presente entrevista en profundidad, podemos visualizar cómo la entrevistada diferencia claramente el porqué de la decisión de sus padres -aunque hace principal hincapié en su madre- de mandarlos a trabajar (a 
ella y luego a sus hermanos) y la justificación que ella misma, en la actualidad como madre, le atribuye a la necesidad de incluir a sus hijas e hijos en las actividades laborales de la familia en el presente. En este sentido al comienzo de la entrevista, podemos visualizar en el relato de la entrevistada cierta presencia de lo elusivo en el discurso (Fernández, 2012). Así, al conversar acerca de su trayectoria laboral y escolar, la entrevistada deja constancia de que hay decisiones significativas que no siendo propias, ha debido asumir a lo largo de su vida. Es interesante visualizar, en término de Genette el pasaje de narrador autodiegético en primera persona "empecé" al heterodiegético "me mandaron". Asimismo, en ocasiones cambia el aspecto verbal de un puntual "me mandaron" a un durativo "me mandaban" a partir del cual se puede inferir que sus efectos no quedan en el pasado sino que perduran en el tiempo, lo que podría relacionarse con los diferentes reclamos, entre ellos el de abandonar el terreno donde se ubica su vivienda, que aún hoy sus padres continúan exigiéndole.

De igual manera es interesante analizar cómo se refiere a sus embarazos. La elección léxica "y bueno así empezaron a venir" da cuenta de lo desarrollado con anterioridad, de la aparente no elección de aquellas circunstancias. En vinculación con esto retomamos a Fernández (op. cit.) en tanto podemos visualizar ciertas fluctuaciones entre "erigirse discursivamente como otro y asumir el lugar de la no persona" (Benveniste, 1974 citado por Fernández, op. cit.: 1) y retomar la primera persona -como veremos en diferentes fragmentos-. El siguiente ejemplo es ilustrativo de lo desarrollado

Ea.-: A trabajar empecé a los 9 años en el saladero, en el descabezado de anchoítas. Este... después bueno fue en el tiempo así, trabajé hasta los 15 años más o menos. A la escuela me mandaron hasta 2 do grado y después mamá y papá me mandaron a trabajar al saladero y dejé de trabajar [confusión] de... ir al colegio. Y bueno después me hice grande [risas], ya después dejé el colegio definitivamente y bueno asi empezaron a venir... Ma. [hija mayor], ya estaba grande y empezaron a venir casi a los 20 años mi hija, la mayor, de 18 años. Pero no, bueno...trabajando, en la lucha.

Edora.: Cuándo empezaste a trabajar: ¿de quién fue la decisión de que empieces a trabajar vos? Ea: De mi papá y de mi mamá, ellos me mandaban. [...] Edora.: ¿Eso fue cuando vos estabas embarazada de Ma.? Ea: No, ya estaba nacida mi hija, tenía 10 días mi hija cuando yo empecé a trabajar. Si... y después más o menos a los 12, 13 años yo ya dejé de trabajar en la fábrica... [...] Y bueno después vino Al. [hijo], y bueno y asi vinieron todos los chicos. Para ver si podía [aseveración en el podía] tener una familia, pero bueno...no tuve la suerte con los papás de los chicos... Ahora con el papá de T. [hijo menor] gracias a dios... buenísimo hace 8 años que está conmigo pero bueno, no nos hace falta la comida y... [...] Edora.: y de la escuela ¿te acordas algo? ¿A qué escuela ibas? ¿Te gustaba? Ea: Si, estaba bueno. Primero fui a la 44 a la que está ahí... [confusión] No, a la 42 fui. Después, bueno, después me mandaron a la 506, porque ya estaba grande, a los 15 años y yo ya no sabía leer ni nada y me mandaron ahí. Y bueno ya después a los 17, 18 dejé el colegio no? tenía 16, 17, 18 años y ya iba a ler grado entonces no... Como nunca me mandaron al colegio, me mandaban a la vista perdida y bueno... 
En este sentido, teniendo en cuenta principalmente el fragmento anteriormente trascripto a modo de ejemplo, consideramos que la diferenciación que la entrevistadora establece entre la situación que ella ha vivido como niña trabajadora y la que sus hijos e hijas viven en el presente da cuenta de las diferentes percepciones que atraviesan las percepciones encontradas en torno a la problemática del trabajo infantil. Mientras la primera de ellas -su situación como niña trabajadora-se asemejaría al discurso standarizado en torno al trabajo infantil, es decir, a lo que la normativa establece y muchas veces desde el prejuicio se cree -esto es, culpabilización a los adultos significativos de los hogares ante situaciones de trabajo infantil, baja estima por la educación y preferencia de actividades laborales en la relación de costo-oportunidad de a educación-, su historia y la de su grupo familiar en el presente da cuenta de prácticas totalmente diferentes, de la presencia de prácticas de trabajo infantil en el marco de la configuración de estrategias familiares de vida que permitan

[...] la constitución y mantenimiento de unidades familiares en el seno de las cuales pueden asegurar su reproducción biológica, preservar la vida y desarrollar todas aquellas prácticas, económicas y no económicas, indispensables para la optimización de las condiciones materiales y no materiales de existencia de la unidad y de cada uno de sus miembros (Torrado, 1985: 3) (Gutiérrez, 2004: 44).

Una mención aparte merece el fragmento de la entrevista en el que, al referirse a las actividades que pueden caracterizarse como trabajo infantil doméstico, la entrevistada hace hincapié en el desarrollo de las mismas por parte de las hijas mujeres. Al mismo tiempo, al referirse a las actividades de este tipo que realiza su hijo varón utiliza la mención "no no se lava sólo, medio mariqui...no, se lava la ropa solito él...". Podemos evidenciar cómo mientras las hijas mujeres realizan actividades domésticas que incluyen a todo el grupo familiar y el mantenimiento del hogar, el hijo varón sólo realiza aquellas que lo incumben específicamente: su ropa, su pieza. La apelación a este tipo de prácticas como prácticas que naturalmente corresponden a la esfera de las actividades de las mujeres se condice con la frecuente segmentación por género de las actividades domésticas, en sociedades que históricamente han sobrecargado desigualmente a las mujeres. Ello, se extiende también al trabajo infantil, es decir que las niñas y adolescentes mujeres suelen ser quienes mayoritariamente realizan éstas actividades tal como lo informa Cutuli, 2009.

\section{A modo de cierre}

El análisis que hemos propuesto, lejos de ser el único y verdadero, es el que hemos elegido para recorrer el discurso de la entrevista. Creemos que no es la realidad -en este caso el discurso- por sí sola la que da lugar al conocimiento permitiendo extraer de ella una interpretación acabada de los sucesos sino, que esa interpretación se da a partir de un recorte determinado - no neutral ni objetivo- que hace el investigador a partir de un marco teórico determinado que permite interpretar y dar significado a la realidad. En este sentido, múltiples serán los análisis posibles tomando como base la entrevista en profundidad aquí presentada.

Tal como afirman Fernández y Hachén (1991)

[...] La lengua standard es la lengua del poder, la que señala los límites de la "normalidad", de la "verdad" y, en definitiva, de lo "real". Todo aquel discurso 
que se aleje de estas normas, de este criterio de "verdad" o de estas formas de referencialización, ingresa en el plano de lo marginal, desempeñando el rol de la ANTICULTURA (Fernández y Hachén, 1991: 2).

El análisis de la entrevista en profundidad aquí presentada nos ha permitido adentrarnos en la vida cotidiana de los sujetos a los que tantas veces se los culpabiliza. Nos ha permitido comprender cómo las prácticas cotidianas interpelan, nuevamente, desde la realidad a las necesarias, pero insuficientes, normativas en relación a la problemática del trabajo infantil. Del mismo modo nos ha posibilitado dar cuenta de la recreación de prácticas lúdicas y de cuidado aun en el marco del desempeño de actividades laborales de niñas, niños y adolescentes.

Resulta interesante analizar la concepción de esta anticultura ya no como la no-cultura, sino como ese otro que aparece, que habla, que resiste, que tiene voz y construye, en definitiva que habla el mundo.

\section{$\underline{\text { Bibliografía }}$}

Charaudeau P. (1982) Language et discours. Eléments de semiolinguistique, Hachette, París, 1988.

Costa, R. \& Mozejko, D. (2001) El discurso como práctica. Lugares desde donde se escribe la historia. Buenos Aires: Ed. Homo Sapiens.

Cutuli, R (2009) Flexibilidad empresarial y organización del trabajo doméstico: el trabajo invisible de las hijas de las fileteras en Mar del Plata (1991-2008). En: Congreso Nacional de Estudios del Trabajo, 9, 5-7 agosto 2009, Buenos Aires. Disponible en línea en: http://nulan.mdp.edu.ar/1267/\#.USJ17B3cme0

Fernandez, M.R y Hachén, R (1991) "Entre la no cultura y la anti-cultura: aproximaciones al análisis del binomio discurso standard/ dis-curso marginal desde una perspectiva semiolingüística" en Papeles de Trabajo del Centro de Ciencias Etnolingüísticas y Antropología Sociocultural N 4, UNR, Rosario. 1995.

Fernández, M.R y Hachén, R (2002) De la enseñanza de la argumentación a la argumentación como estrategia de enseñanza. La instancia de corrección. Ponencia presentada en Simposio de la Cátedra UNESCO: Enseñanza de la argumentación, Buenos Aires, julio. En Actas. Buenos Aires, Instituto de Lingüística, Fac. Filosofía y Letras, UBA. Pág. 1341- 1352.

Fernandez, M.R \& Hachén, R (2006) HABLAR EL MUNDO. Fundación de Patrimonio Histórico, Rosario, versión electrónica

Fernandez, M. R (2012) "Estrategias alusivas/elusivas en el discurso: el pronunciamiento de la CONACAMI de noviembre de 2011". Revista de Antropología Nro. 17. Rosario: Facultad de Humanidades y Artes, UNR.

Gutierrez, A. (2004) Pobre', como siempre... Estrategias de reproducción social en la pobreza. Argentina: Ed. Ferreyra.

Hachén, R. (1999) "Querer/ deber / poder / saber: la lectura en la encrucijada del tabú y la libertad". Revista de Letras $\mathrm{N}^{\circ}$ 6, Facultad de Humanidades y Artes, UNR. ISSN N ${ }^{\circ}$ 0328-8889.

Lo Cascio, V. (1991) Gramática de la argumentación. Ed. Alianza, Madrid, 1998

Macri, M (2011) "Trabajo infantil y familia: Los estudios sociológicos sobre la familia como marco interpretativo para el trabajo infantil intrafamiliar", en Flah, L, Fodor, S y 
Del Arbol, M (2011) Los desafíos del derecho de familia en el siglo XX. Buenos Aires: ERREPAR.

Macri, M, Ford, M, Berliner, C y Molteni, M (2005) El trabajo infantil no es juego. Buenos Aires: Editorial Stella-La Crujía Ediciones.

Maingueneau, D. (2004) ““'Situación de enunciación” o"situación de comunicación”?" Université Paris XII, Año 3, Número 5. ISSN 1666-3519. Disponible en: http://es.scribd.com/doc/98809453/Maingueneau-D-2004-Situacion-de-enunciacion-osituacion-de-comunicacion

Marafioti, R. (1997) Recorridos semiológicos. Signos, enunciación y argumentación. Buenos Aires: EUDEBA.

Pedraza Gómez, Z. (2007) "El trabajo infantil en clave colonial: consideraciones histórico-antropológicas". Revista nómadas n 26. Páginas: 80-90. Universidad Central. Colombia.

Portolés, J. (1998) Marcadores del discurso. Barcelona: Ed. Ariel.

Torrado, S (1985) El enfoque de las estrategias familiares de vida en América Latina. Orientaciones teórico metodológicas. Buenos Aires: cuadernos del CEUR.

Vasilachis de Gialdino, I. (2006) Estrategias de investigación cualitativa. España: Gedisa

Weinrich, H (1979) Le temps, Du Seuil, Paris 